\title{
Effective Sports Coaching: A Systematic Integrative Review
}

\section{[PREPRINT]}

Kyran Clements and John P. Mills

University of Essex, School of Sport, Rehabilitation, and Exercise Sciences, Wivenhoe Park, Colchester, Essex, CO34SQ, United Kingdom

Corresponding Author email: john.mills@essex.ac.uk

Keywords: Coaching Effectiveness, Coaching Efficacy, Sport Coaching, Critical Review, Sports

Mills, J. P., \& Clements, K. (2021, June 10). Effective Sports Coaching: A Systematic Integrative Review. Retrieved from osf.io/58ypu 


\begin{abstract}
Research investigating coaching effectiveness is of great importance to ensure the sporting experience and development of athletes is optimised. Coaches are significant figures for the athletes they coach, especially for youth athletes within sporting programmes. Therefore, understanding what makes an 'effective coach' in terms of leadership and coaching behaviours will only aid positive youth development and help ensure youth athletes are afforded optimal opportunities to enhance their skills and attributes. This systematic review aims to present a comprehensive review of the coaching effectiveness literature. A systematic search was conducted of four electronic databases: PsycArticles, PsycINFO, SPORTDiscus, and Web of Science. Scholarly peer-reviewed studies published in English were included in this review. The initial search yielded 137 papers, with 45 papers retained and referenced within the review following screening. Studies either developed a measurement tool to assess coaching behaviour, evaluated a measurement tool, or employed such tools in studies assessing sources, dimensions or outcomes of coaching behaviour.

Overall, the review offers support for the importance of athletes' perceptions of coaching behaviours in shaping an athletes' psychological development and well-being. Understanding athlete perceptions of effective coaching behaviours and how they impact specific outcomes may help to improve positive development in youth athletes.
\end{abstract}




\section{Effective Sports Coaching: A Systematic Integrative Review}

Coaches play an influential role in guiding the learning and development of athletes, and are often described as leaders of the athletes they coach (Kassim \& Boardley, 2018; Mills \& Boardley, 2016; Vella et al., 2010). Particularly important in youth development programmes (Côté \& Gilbert, 2009), coach leadership behaviours can impact upon performance and developmental outcomes in athletes (Kavussanu et al., 2008; Mills \& Boardley, 2017; Vella et al., 2010). Within sport psychology, and specifically coaching science literature; there has been a pursuit to understand and recognise what it means to be an “effective coach" (Côté \& Gilbert, 2009; Horn, 2002, 2008). The literature suggests that effective coaches are those who exert a positive influence on their athletes through their behaviours (Horn, 2002; Smith et al., 1979; Smoll \& Smith, 1989). An initial definition of coaching effectiveness was proposed by Boardley et al. (2008), who defined coaching effectiveness as 'the extent to which coaches can implement their knowledge and skills to positively affect the learning and performance of their athletes'. The coaching science literature further suggests that effective coaches not only guide the development of sport specific skills and knowledge, but are in fact instrumental in the overall development of athletes, including areas such as psychological well-being and moral development (Broodryk et al., 2014; Côté \& Gilbert, 2009; Horn, 2002). The purpose of the present review was to provide an up-to-date and comprehensive summary of the effective coaching literature, reviewing studies that encompass the origins and development of effective coaching. A significant contribution to this area of research is the work of Côte and Gilbert (2009), who presented an integrated definition of coaching effectiveness. Extending on the work of Lyle (2002), as well as the research on effective teaching, Côté and Gilbert (2009) 
distinguished between coaching expertise, effective coaching, coaching effectiveness and what constitutes being an expert coach. They suggested that coaching expertise refers to specific knowledge in particular contexts, whereas effective coaching is the ability to apply and align coaching expertise to particular athletes and situations in order to maximize athlete learning outcomes. Côté and Gilbert (2009) defined coaching effectiveness as "the consistent application of integrated professional, interpersonal, and intrapersonal knowledge to improve athletes' competence, confidence, connection, and character in specific coaching contexts". They stated that a coach can be considered effective if they demonstrate coaching effectiveness, and those who demonstrate coaching effectiveness over an extended period of time may then be considered an expert coach.

Côté and Gilbert (2009) proposed that there are three key components that provide the foundations of their definition of coaching effectiveness: coaches' knowledge, athletes' outcomes, and coaching contexts. They indicated that coach knowledge not only includes the commonly investigated area of professional knowledge (sport-specific knowledge), but also extends to include both interpersonal (interaction with others) and intrapersonal (understanding of oneself and the ability for introspection and reflection) forms of knowledge. The athletes' outcomes component incorporates the 4C's framework (competence, confidence, connection and character) of positive youth development. Côté and Gilbert (2009) propose that these four constructs should be developed in athletes as a result of effective coaching. They stated competence consisted of sport-specific technical and tactical skills, performance skills, improved health and fitness and healthy training habits. Confidence was defined as an internal sense of overall positive self-worth. Connection was identified as the development of positive bonds and social relationships with people inside and outside of 
sport. Lastly, character was referred to as respect for the sport and others (morality), integrity, empathy and responsibility.

The third and final component, coaching contexts, concerns the varied sport settings in which coaching can take place. They identified four coaching contexts, based on a participation-performance continuum and the developmental spectrum of athletes from children to adults. The four contexts are: 1) participation coaches for children (sampling years), 2) participation coaches for adolescents and adults (recreational years), 3) performance coaches for young adolescents (specializing years), and 4) performance coaches for older adolescents and adults (investment years).

Côté and Gilbert (2009) proposed that even though the type of knowledge required by coaches in different sporting contexts varies, the 4C's remain stable as indicators of athlete outcomes and coaching effectiveness. The definitions adopted by Côté and Gilbert (2009) for the four outcomes of effective coaching (4C's) are more broad in comparison to others traditionally adopted in the sport psychology literature. This may reflect a view that they deem coaching effectiveness to extend further beyond the impact of coaching within the specific environment or situation in which it occurs. Therefore, the integrative definition of coaching effectiveness proposed by Côté and Gilbert (2009) suggests that effective coaches are those who in any context, apply an appropriate blend of professional, interpersonal and intrapersonal knowledge to develop the 4C's in athletes and meet specific athlete needs.

The work of Côté and Gilbert (2009) expands upon the model of coaching effectiveness proposed by Horn $(2002,2008)$. This model of coaching effectiveness is based on three assumptions. The first is that the sociocultural context, the organisational climate and the coach's personal characteristics influence a coach's behaviour indirectly through a coach's expectancies, values, beliefs and goals. Second, is that coach behaviour directly 
influences athletes' perceptions and evaluations of their coach's behaviour, with such perceptions being affected by athletes' personal characteristics or individual differences. Third, athletes' perceptions and evaluations of their coach's behaviour will impact upon athletes' self-perceptions, beliefs and attitudes, which in turn affects athletes' motivation and performance. This model highlights the fundamental importance of athletes' perceptions and evaluations of their coach in determining coaching effectiveness with regard to the influence of coaching behaviours on athlete-level outcomes.

To form the model of coaching effectiveness, Horn $(20002,2008)$ included elements of the Mediational Model of Leadership (Smoll \& Smith, 1989). The work of Smoll and Smith (1989) similarly suggested that coaches' behaviours exert influence on athletes via athletes' perceptions. They found that athlete-related outcomes (e.g. athlete participation and satisfaction) as a result of coaching behaviours, were frequently mediated by the meaning that players gave to such behaviours. The framework proposed that coaching effectiveness is determined by the evaluative reaction of athletes' based on their perception and recall of a coaches' behaviour. Situational factors, (e.g., nature of the sport,level of competition, etc.), coach/athlete personal characteristics and individual differences (e.g., age, sex, goals, sport experience, etc.) and the coach's perception of athletes attitudes were included in the model as mediating variables which may have an affect on the central process.

Another framework that has been useful in guiding research on coaching effectiveness is the coaching efficacy model; a conceptual model introduced by Fetlz et al. (1999) which considers factors central to the coaching process. The model was conceptualised based upon Park's (1992) initial measure of coaching confidence and Denham and Michael's (1981) model of teacher efficacy. Bandura's (1997) theory of self-efficacy was also used as a key guiding framework in the development of the coaching efficacy model and the construct of 
'coaching efficacy' itself. Bandura $(1977,1986,1997)$ defined self-efficacy as 'the belief in one's capabilities to organise and execute the courses of action to produce given attainments'. Self-efficacy is described as one of the most powerful psychological constructs deemed to mediate achievement endeavours in sport (Feltz, 1988).

Viewing coaching efficacy as a coach-specific form of self-efficacy, Feltz et al. (1999) defined coaching efficacy as 'the extent to which coaches believe they have the capacity to affect the learning and performance of their athletes'. Coaching efficacy was stated to be multidimensional, consisting of four dimensions that contribute to a coach's total coaching efficacy: motivation, game strategy, technique and character-building. Motivation efficacy is the confidence coaches have in their ability to affect the psychological skills and motivational states of their athletes. Game strategy efficacy refers to the confidence coaches have in their ability to coach during competition and lead their team to a successful performance.

Technique efficacy is the belief coaches have in their instructional and diagnostic skills. Lastly, character-building efficacy concerns the confidence coaches have in their ability to influence the personal development of their athletes and promote a positive attitude towards sport. These four dimensions were devised as the result of a 5-week seminar involving 11 coaches who were graduate students in sport psychology with varying levels of coaching experience. The National Standards for Athletic Coaches (1995) and Park's (1992) exploratory factor analysis of coaching confidence were used as the grounding for discussions of the key components of coaching efficacy. Aspects of effective coaching repeatedly mentioned throughout the coaching education literature were also identified, and following the discussions with coaches, were reduced to the four key dimensions used in the model. As a result, the dimensions of coaching efficacy are consistent with essential elements of effective coaching. 
The coaching efficacy model proposed that there are certain sources of coaching efficacy which influence coaching efficacy dimensions. These sources include the extent of coaching experience and preparation, prior success, perceived skills of athletes, and perceived social support from schools and the community. The model also suggests that high levels of coaching efficacy should lead to a number of desirable outcomes for both coaches and athletes. Coaching efficacy should influence coaching behaviour, including the type of feedback used, management strategies, and coaching styles. It was also proposed that higher levels of coaching efficacy should also result in higher levels of athlete and team satisfaction, increased athlete and team performance, and higher levels of athlete and team efficacy.

In addition to proposing a conceptual model that outlined the main sources, dimensions and outcomes of coaching efficacy; Feltz et al. (1999) also developed a valid and reliable tool to assess coaching efficacy. The Coaching Efficacy Scale (CES), a 24-item multidimensional self-report questionnaire, measures the four dimensions of coaching efficacy that emerged from the seminar. The seminar led to the generation of 41 items, but following factor analysis results, 17 of the original items were later dropped. The stem "How confident are you in your ability to..." preceded the items, with each of the 24 items corresponding to a specific dimension of coaching efficacy.

Boardley (2018) recently proposed a revised conceptual model of coaching efficacy. Incorporated within the revised model is the work of Côté and Gilbert (2009), with developments in the revised model linking to the coaching contexts and athlete outcomes components of coaching effectiveness. One development is that in the revised conceptual model, coaching experience as a source of coaching efficacy information is deemed to be most influential when it is specific to the coaching context in which coaching efficacy is being considered. A second development from the original model is that athlete outcomes are 
now grouped under the $4 \mathrm{C}$ 's categorisation of athlete-level outcomes of effective coaching. The revised model proposes that coaching efficacy influences athlete-level outcomes through athletes' perceptions of their coach's efficacy based on their coach's behaviour. This is consistent with Côté and Gilbert's (2009) work, where perceptions of coaching effectiveness may be predictive of athletes' outcomes. Categorising athlete-level outcomes in this 4 C's format enables the identification and evaluation of measurable indicators of effective coaching. A further development of the revised model is that it distinguishes between athleteand team-level outcomes when identifying the $4 \mathrm{C}$ 's due to a large proportion of coaching being delivered in team or group environments.

\section{Methodology}

\section{Inclusion and exclusion criteria}

The general inclusion criteria for this review required that studies were: (a) published in English, (b) published in peer-reviewed journals (c) within sport and psychology-based contexts. Further inclusion criteria stipulated that studies: (d) were original research or reports published in peer-reviewed journals (e) examined the mechanisms, processes, and outcomes of coaching (f) published between 1975-2020. Exclusion criteria for this review were: (a) paper not published in English, (b) paper published before 1975, (c) paper was not relevant to sport coaching.

\section{Identification of papers}

A systematic search of four electronic databases was conducted for relevant documents aligning with the aims of this review. The databases searched were ESBSCOhost (which included PsychARTICLES, PsychINFO, and SPORTDiscus) and Web Of Science. To search these databases, a combination of keywords and search terms were employed. These 
keywords and search terms constituted two groups: (a) coaching effectiveness or coaching efficacy or effective coaching and (b) competence or confidence or connection or character, with each database search combining the keywords from both groups. Quotation marks were used to surround search terms to ensure terms were searched as an exact phrase. The search was conducted in December 2019 and updated in February 2020. To supplement the database searches, the reference lists of all extracted articles were scanned to identify any additional relevant studies.

\section{Study screening and selection}

Papers concerning coaching effectiveness, coaching efficacy, effective coaching and athlete development, identified from the electronic search of the aforementioned databases, were screened in a process following the PRISMA guidelines (Moher et al., 2009) for systematic reviews and meta-analyses. In phase 1, all extracted articles were combined into a single folder, with duplicates being removed. Titles and abstracts were screened in phase 2 , excluding any immediate unrelated articles. In phase 3, the full text of articles was reviewed, scanning and reviewing their adherence to the inclusion criteria. Phase 4 involved the screening of the reference lists of the full-text articles assessed.

\section{Data extraction}

Studies meeting the review criteria were re-reviewed and specific information from the articles were extracted and collated into a separate standardised form. The extracted information and data included: (a) author, (b) year of publication, (c) sample characteristics (i.e. number of participants, gender, age), (d) study aims, (e) study method, (f) measures of 
coaching behaviour, (g) study findings. Collectively, this information enabled the assessment of the state of the current literature and to provide directions for future research.

\section{Results}

\section{Search results}

The initial search identified 137 studies $($ PsychArticles $=2$, PsychINFO $=43$, SPORTDiscus $=47$, and Web of Science $=45$ ). After excluding duplicates there were 84 articles. The abstracts and titles of these articles were screened, where 51 articles were excluded from the review. The full-text and reference list was screened for each of the 33 selected articles. 22 papers from the reference lists were selected. A total of 46 papers were included in the review (Figure 1).

[Insert Figure 1 here]

\section{Description of studies}

Out of the 46 papers included in this review, a total of 18 studies assessed coaches' perceptions of coaching efficacy, utilising the original coaching efficacy scale proposed by Feltz et al. (1999) to assess coaching efficacy. Of these 18 studies, eight investigated sources of coaching efficacy (Campbell \& Sullivan, 2005; Fung, 2002; Kavussanu et al., 2008; Malete \& Feltz, 2000; Malete \& Sullivan, 2009; Short et al., 2005; Thelwell et al., 2008; Tsorbatzoudis et al., 2003), six investigated outcomes of coaching efficacy (Chow et al., 2009; Kealthoestwe \& Malete, 2019; Kent \& Sullivan, 2003; Malete et al., 2013; Sullivan \& Kent, 2003; Vargas-Tonsing et al., 2003), and three investigated both sources and outcomes of coaching efficacy (Feltz et al., 1999; Hwang et al., 2013; Myers, Vargas-Tonsing et al., 
2005). One study investigated levels of coaching efficacy to plan for future coach preparation programmes (Fung, 2003).

Of the 46 papers included in this review; 10 studies involved assessing coaching efficacy through either evaluations of, and/or revisions to, the original coaching efficacy scale (Feltz et al., 1999). Specifically, two studies evaluated the psychometric properties of the CES (Myers, Wolfe et al., 2005; Tsorbatzoudis et al., 2003). Two studies (Hepler et al., 2007; Myers, Feltz et al., 2008) tested the condensed rating scale of the CES proposed by Myers, Wolfe et al. (2005). Two studies used the condensed rating scale of the CES to assess sources of coaching efficacy (Hepler et al., 2007; Feltz et al., 2009). Two studies proposed revised versions of the CES (Myers, Chase et al., 2011; Myers, Feltz, Chase et al., 2008). Two studies used the CES II-HST to investigate coaching efficacy (Myers, Feltz et al., 2011; Sullivan et al., 2012). One study conducted a meta-analysis (Myers et al., 2017).

Of the 46 papers included in this review, 21 studies investigated athletes' perceptions of their coach. Specifically, four studies examined athlete perceptions of coach behaviour (Smith et al., 1978; Kenow \& Williams, 1992; Kenow \& Williams, 1999; Vargas-Tonsing et al., 2004). Four studies investigated athletes' perceptions of their coach's efficacy (Atkinson et al., 2018; Boardley et al., 2015; Short \& Short, 2004; Teatro et al., 2017). Eight studies investigated athletes' perceptions of their coach's competency (Boardley \& Kavussanu, 2009; Boasselut et al., 2012; Malete, 2013; Myers, 2013; Myers et al., 2010; Myers, Beauchamp et al., 2011; Myers, Feltz et al., 2006; Myers, Wolfe, et al., 2006). Five studies investigated athletes' perceptions of their coach's effectiveness (Boardley et al., 2008; Broodryk \& Van Den Berg, 2011; Broodryk et al., 2014; Kassim \& Boardley, 2018; Kavussanu et al., 2008).

\section{Critical Review}




\section{Coaches' perceptions of coaching efficacy}

\section{Utilisation of the coaching efficacy scale (CES)}

Feltz et al. (1999) provided preliminary support for the conceptual model of coaching efficacy using the CES and a separate sample of male high school basketball coaches $(n=69)$ to what was used in the preliminary scale development and internal factor structure of the model. Preseason data was collected to investigate a range of sources of coaching efficacy. Pearson correlations found that a coach's past success, coaching experience, perceived team ability and perceived social support from parents and the community had moderate positive relationships with at least one dimension of coaching efficacy. The motivation efficacy dimension of coaching efficacy was found to have the highest number of meaningful positive relationships with the sources investigated, whereas the character building efficacy dimension failed to show any meaningful relationships. Feltz et al. (1999) also investigated the outcomes of coaching efficacy proposed in the coaching efficacy model. The pre season data collected from the 69 coaches was used to identify the 15 coaches with the highest coaching efficacy beliefs, and the 15 coaches with the lowest coaching efficacy beliefs. A trained observer then observed two training sessions of 29 of the 30 coaches identified, recording the frequency of various coaching behaviours. The players being coached were assessed on their satisfaction with their coach during the second training session observed, and postseason, coaches were then assessed for how much time they perceived they had spent coaching during the season and for their commitment to coaching. Comparisons between high and low efficacy coaches using t-tests found that high-efficacy coaches had higher win percentages, provided more praise and encouragement, used less instructive and organisational behaviour and had more satisfied players compared to low-efficacy coaches. However, no differences were identified between high and low efficacy coaches in terms of their commitment to 
coaching, amount of perceived coaching effort and their use of punishment and control behaviours. A considerable amount of research has since used the CES as a measuring tool to determine coach perceptions of their own coaching efficacy, aiming to provide empirical evidence for the sources, dimensions and outcomes of coaching efficacy proposed by Feltz et al. (1999). Researchers have also sought to use the CES questionnaire to investigate the effects of coaching efficacy on other potential outcomes.

Malete and Feltz (2000) examined the effect of participation in a coaching education programme on coaches' perceived coaching efficacy. A quasi-experimental design was used, with an experimental group consisting of high school coaches, and a mix of coaching preparation students and coaches without any formal coaching education forming a control group. Coaches in the experimental group were exposed to the 'Program for Athletic Coaches Education' (PACE) (Seefeldt \& Brown, 1990) a 12-hour programme covering areas relevant to the coaching efficacy dimensions. Both groups were administered the CES (Feltz et al., 1999) questionnaire pre and post PACE programme. Analyses revealed significant differences between both groups post-test, and found a significant increase in coaching efficacy for coaches exposed to the programme pre and post-test, with game strategy and technique efficacy showing the strongest increase. Although providing additional construct validity for the CES (Feltz et al., 1999), the CES scores of all participants were rather high, even at pre-PACE participation, with no significant differences between the two groups at pre-test.

Campbell and Sullivan (2005) similarly used the CES (Feltz et al., 1999) when examining the effect of a coaching education programme on coaches' efficacy, whilst simultaneously investigating gender differences in this effect. Coaches completed the CES prior to the beginning of the coaching programme and immediately following the 
programme. Their results provided further support for the CES (Feltz et al., 1999), finding that there was a significant increase in the four coaching efficacy dimensions (motivation, technique, game strategy and character building) after completing the programme. The results further suggested that in terms of the motivation and character building subscales, females perceived themselves to be significantly more efficacious than males.

In a study of 252 community coaches working with beginner and district-level athletes in a variety of sports in Hong Kong, Fung (2002) used the CES (Feltz et al., 1999) questionnaire to establish a profile of coaching efficacy. The coaching efficacy dimension in which coaches reported the greatest efficacy was motivation, but coaches with less coaching experience were less confident about motivating their athletes compared to their more experienced counterparts. No association was found between coaching accreditation level and hours of coaching in the past year and coaching efficacy. A further study by Fung (2003) assessed 74 high school coaches attending a school coach certification programme offered by an official body responsible for a territory-wide coach accreditation system in Hong Kong. To gain an insight for planning future coach preparation programmes, the CES (Feltz et al., 1999) questionnaire was administered to identify the level of coaching efficacy of the coaches in the sample. Participating coaches reported themselves as most efficacious for the character-building dimension, but the dimension they felt the least efficacious was game strategy.

Tsorbatzoudis et al. (2003) used the Greek translation of the CES (Tsorbatzoudis et al., 2000) to examine the impact of coaching experience upon perceived coaching efficacy of 230 Greek male team-sport coaches. The questionnaires were administered during four annual seminars organised by the Greek handball, basketball, volleyball and soccer federations, with participants being asked to report how confident they were about their skills 
to lead their team successfully and how supported they were by team members. During analysis, coaches were divided into experienced and less experienced groups. Experienced coaches, $52.6 \%$ of the total sample, had more than 5.5 years of coaching experience. Results from a $t$ test analysis showed significant differences between experienced and less experienced coaches for the technique dimension and for overall coaching efficacy, with more experienced coaches having significantly higher scores.

A study by Sullivan and Kent (2003) used the CES (Feltz et al., 1999) as a tool to examine the relationship between the efficacy of 223 male and female American and Canadian intercollegiate coaches and their leadership style. Results demonstrated motivation and technique efficacy to be significant positive predictors of training and instruction engagement, as well as positive feedback behaviours. They also reported that democratic behaviours were not predicted by any dimension of coaching efficacy, and predictive analyses of autocratic behaviour and social support were not conducted due to poor internal consistency of these leadership behavioural styles. Kent and Sullivan (2003) explored the relationship between organisational commitment (commitment to coaching) and coaching efficacy using the CES (Feltz et al., 1999). In their analyses, a second order factor model of coaching efficacy significantly predicted both affective and normative commitment of the 212 participating intercollegiate head coaches.

Additional support for the coaching efficacy model (Feltz et al., 1999) is the work of Vargas-Tonsing et al. (2003). They explored team-efficacy and players self-efficacy beliefs as outcomes of coaching efficacy in a study with female volleyball coaches and athletes. Multiple regression analyses revealed coaching efficacy significantly predicted team-efficacy, but there was no meaningful association between coaching efficacy and player self-efficacy. Motivation efficacy and character building efficacy were found to be the strongest predictors 
of team-efficacy. Motivation efficacy was a positive predictor, whereas character building efficacy was a negative predictor of team-efficacy.

Imagery was investigated as a source of coaching efficacy in a study by Short et al. (2005). Regression analyses identified that motivation general - mastery imagery positively predicted overall coaching efficacy, motivation efficacy and character building efficacy. Analyses found that cognitive general imagery positively predicted game strategy efficacy, and cognitive specific imagery positively predicted technique efficacy, suggesting imagery may be an effective method if improving coaching efficacy.

Myers, Vargas-Tonsing et al. (2005) investigated sources and outcomes of coaching efficacy. Male and female head coaches of intercollegiate athletes from softball, baseball, soccer and basketball teams reported their frequency of engagement in 13 strategies suitable for increasing athletes' confidence. This study offers support for the coaching efficacy model and the CES (Feltz et al., 1999) by showing relationships between the sources and dimensions of coaching efficacy. Significant positive relationships were found between years as a collegiate head coach, career winning percentage, perceived team ability, parental support, and community support and specific dimensions of coaching efficacy. Motivation efficacy was found to have the strongest and greatest number of associations, whereas technique efficacy was found to have the least meaningful associations. The source of coaching efficacy identified to have the strongest association with all dimensions of coaching efficacy was perceived team ability, whereas the weakest effects were seen for collegiate coaching experience. They also identified that total coaching efficacy positively predicted outcomes such as coaching behaviour, team satisfaction and winning percentage for men's teams. However, total coaching efficacy predicted only coaching behaviour across women's teams, and was only significant for female coaches. This highlights the importance of 
considering coach/athlete gender match or mismatch when investigating the outcomes of coaching efficacy.

Kavussanu et al. (2008) measured coaches' perceptions of their own coaching efficacy using a sample of head coaches of British university athletes. They identified that neither coaching experience nor sex of coach significantly predicted motivation or character building efficacy. However, results did show that coaching experience positively predicted technique efficacy and sex of coach predicted game strategy efficacy, with male coaches in the sample reporting significantly higher game strategy efficacy than their female counterparts. A possible explanation for the latter finding is that males emphasize winning more than females, and therefore male coaches may tend to spend more time developing athletes in terms of their skills to lead them to success during competition.

Further research using the CES (Feltz et al., 1999) as a measuring tool to determine coach perceptions of their own coaching efficacy includes the work of Thelwell et al. (2008). They explored how emotional intelligence constructs relate to the dimensions of coaching efficacy. They found that both the coaches' appraisals of their own emotions and regulation of emotions were significantly correlated with all subscales of the CES (Feltz et al., 1999), as well as total coaching efficacy. Thelwell et al. (2008) also found that regulation of emotions and social skills were significant predictors of motivation efficacy, optimism significantly predicted character building efficacy, and coaches' appraisal of their own emotions was a significant predictor of technique efficacy. However, they did not identify any significant predictors of game strategy efficacy. Hwang et al. (2013) similarly investigated the relationships between the emotional intelligence and the coaching efficacy of head coaches of high school basketball teams, with structural equation modelling identifying a strong positive effect of emotional intelligence on coaching efficacy. A moderate-to-strong positive effect 
was also found between coaching efficacy and leadership style. Leadership behaviours included: training and instruction, democratic, social support, positive feedback, and situation consideration. It was also found that coaching efficacy partially mediated the effects of emotional intelligence on leadership style.

Malete and Sullivan (2009) investigated sources of coaching efficacy, finding that playing and coaching experience were significant sources, and that there was a significant difference between certified and non-certified coaches in terms of their reported coaching efficacy. Chow et al. (2009) investigated the relationship between coaching efficacy and players' self-reported likelihood to aggress. Results from the study demonstrated soccer coaches' game strategy efficacy positively predicted soccer players' likelihood to aggress, whereas character building efficacy had no significant positive effect. This unexpected finding was suggested to be due to coaches with a high level of game strategy efficacy potentially being more likely to promote and positively reinforce unfair but strategically advantageous aggressive or impulsive behaviours to overcome a challenging competitive situation in order to win. Malete et al. (2013) investigated the influences of coaches' perceptions of their own coaching efficacy on two anti-social athlete behaviours: peer cheating and aggression. Analyses in this study revealed that neither game strategy nor character building efficacy were found to significantly predict athletes' self-reported likelihood to engage in the anti-social behaviours assessed. The difference in findings between Chow et al. (2009) and Malete et al. (2013) may have been due to additional variables included in the analyses conducted by Malete et al. (2013), or possibly due to differing moral climates between samples.

Examining Botswana Premier League soccer players and their coaches, Keatlholetswe and Malete (2019) aimed to identify if coaching efficacy beliefs were predictive of player 
perceptions of their coaches' leadership styles, team atmosphere and team performance. They found that overall, coaches rated themselves high on all four of the coaching efficacy dimensions, particularly character building and technique efficacy. Keatlholetswe and Malete (2019) also found that coaches' technique efficacy beliefs predicted player perceptions of the coaches' use of all six investigated leadership styles, including autocratic leadership behaviour. On the other hand, results showed that coaches' self-reported motivation efficacy did not significantly predict player perceptions of the coaches' use of any of the leadership styles. Findings also showed that character building efficacy was negatively associated with the leadership styles assessed, whilst game strategy efficacy beliefs predicted higher team atmosphere and team performance.

\section{Evaluations and revisions of the coaching efficacy scale}

Tsorbatzoudis et al. (2003) examined the psychometric properties of the CES, using the Greek translation of the CES (Tsorbatzoudis et al., 2000). A first-order confirmatory factor analysis supported the basic factorial structure of the scale. A second-order confirmatory factor analysis showed satisfactory fit for a higher order model consisting of an overall coaching efficacy factor. Their findings supported the construct validity and internal consistency of the original form of the CES (Feltz et al., 1999), and also supported the reliability and validity of the Greek version of the scale (Tsorbatzoudis et al., 2000).

Myers, Wolfe et al. (2005) evaluated the psychometric properties of the CES (Feltz et al., 1999) instrument from previously collected data on high school and college level coaches from the United States. They demonstrated the ineffectiveness of the original rating scale structure, reporting that coaches were being asked to distinguish between too many levels of coaching efficacy. They recommended the use of a reduced category rating scale structure, 
because their analysis of the original rating scale suggested coaches did not systematically employ the 10-point rating scale structure. Finding that only $1 \%$ of coaches used the lower end of the scale from $0-4$, they suggested that users of the CES should implement a 4-category rating scale structure. Myers, Wolfe et al. (2005) further suggested that a 5-category structure may be effective for coaches of youth sports because they may be more likely to employ categories on the lower end of the scale. It was also concluded from their analysis that there was limited discriminant validity among the game strategy and technique efficacy dimensions, and that the operational definition for each dimension should be reconsidered. The authors further concluded that several items needed to be revised and/or dropped, and that the resulting measures were relatively imprecise.

Employing the condensed rating scale recommendations of Myers, Wolfe et al. (2005); Hepler et al. (2007) assessed the validity of the CES among 492 volunteer youth sport coaches from various sports including ice hockey, basketball, football, softball, volleyball, and soccer. A confirmatory factor analysis (CFA) was conducted, indicating that the CES was a marginally acceptable fit for the data, supporting previous findings regarding the validity of the CES (Feltz et al., 1999; Myers, Wolfe et al., 2005). Hepler et al. (2007) also explored the sources and of coaching efficacy and how they predicted the coaching efficacy of youth sport coaches. Multivariate multiple regression and canonical correlation analyses indicated that more efficacious coaches had greater playing and coaching experience, perceived their players to have improved more throughout the season, and perceived they received more support than less efficacious coaches. This was particularly evident in regards to the technique and game strategy efficacy dimensions of coaching efficacy.

To extend the validity for the coaching efficacy measures derived from the CES, Myers, Feltz et al. (2008) also tested the condensed rating scale recommendations of the CES 
(Myers, Wolfe et al., 2005). This research, using 492 youth sport coaches, provided confirmatory cross-validation evidence for the use of both 5-category and 4-category structures. It was concluded by the authors that when CES items are used to measure coaching efficacy, the 4-category structure is more suitable. The condensed 5-category structure of the CES recommended by Myers, Wolfe et al. (2005) was utilised in a study by Feltz et al. (2009), to examine the sources that predict the dimensions of coaching efficacy in volunteer youth sport coaches. The authors found that internal support and perceived player improvement positively predicted character building efficacy, and coaching experience, playing experience, internal support, and perceived player improvement positively predicted game strategy efficacy. Feltz et al. (2009) also found coaching experience, playing experience, player improvement and external support positively predicted technique efficacy. The results of this study support existing research, and also identify specific sources of coaching efficacy for the population investigated.

With coaching efficacy being an important variable in models of coaching effectiveness, Myers, Feltz, Chase et al. (2008) put forth a revised version of the CES (Feltz et al., 1999) aiming to improve the measurement of coaching efficacy. The Coaching Efficacy Scale II-High School Teams (CES II-HST), was developed for head coaches of high school teams in accordance with the existing relevant literature and under the guidance of content experts. Myers, Feltz, Chase et al. (2008) added a new dimension of coaching efficacy within the CES II-HST, 'physical conditioning', and provided validating evidence for close model-data fit and for factorial invariance by gender of the coach.

Evidence in support of the validity of the CES II-HST was provided by Myers, Feltz et al. (2011) in a study investigating whether sources of coaching efficacy predict the measures derived from the CES II-HST. Analyses in this study found that the size of the 
effect sources had upon the dimensions of coaching efficacy differed by coach gender. In addition, each of the effects Myers, Feltz et al. (2011) identified were only significant for females. Career winning percentage was found to have a positive effect on game strategy and physical conditioning, but motivation was negatively affected by the team's prior success. They reported that in comparison to male coaches, female coaches prior success was a stronger source of game strategy and motivation efficacy, and female coaches perceived skill of athletes was a stronger source of technique efficacy.

Using Structural equation modelling (SEM), Sullivan et al. (2012) assessed the predictive effects of coaching context and coach education on coaching efficacy using the CES II-HST (Myers, Feltz, Chase et al., 2008). Analysis demonstrated no effect of coaching context on coaching efficacy, but revealed a moderate positive effect of coach education on coaching efficacy. Coaching efficacy was found to positively predict coach leadership behaviours, including: training and instruction, positive feedback, social support, and situational consideration. These findings provide support for the use of the CES II-HST and for the positive effect coach education has as a source of coaching efficacy upon total perceived coaching efficacy.

A substantive-methodological synergy was provided by Myers, Chase et al. (2011), where a revised version of the CES (Feltz et al., 1999) was developed for head coaches of youth sport teams in order to improve the measurement of coaching efficacy. Exploratory structural equation modelling (ESEM) was used to develop the CES II-YST. Myers, Chase et al. (2011) offered evidence for close model-data fit using single-group ESEM, and provided evidence for partial factorial invariance by coach gender using multiple-group ESEM.

A meta-analysis was conducted by Myers et al. (2017) to empirically amalgamate findings from existing literature in order to estimate relationships between the proposed 
sources and dimensions of coaching efficacy. A total of 20 studies were included in the analysis, with a total sample size across all studies equal to 3,597 participants, of which $76.93 \%$ were male. Overall, a positive relationship was found between the proposed sources and each dimension of coaching efficacy, with each relationship ranging from small to medium in effect size. The analysis revealed coach gender and level coached moderated the overall relationship between the proposed sources of coaching efficacy and each of the dimensions. In each case, the relationship was stronger for female coaches in comparison to male coaches, and in the majority of cases, the relationship seemed to be strongest at the collegiate level. Findings from the meta-analysis provided some supporting evidence for the coaching efficacy model (Feltz et al., 1999), in which the proposed sources of coaching efficacy relate to the dimensions of coaching efficacy. Providing reinforcement for the use of the model, and the revisions to the model that have been proposed, the work by Myers et al. (2017) suggests the model continues to be competent for determining the most important sources of coaching efficacy among different coaching categories and levels.

\section{Athletes' perceptions of their coach}

With Feltz et al. (1999) proposing that high levels of coaching efficacy lead to more effective coaching behaviours; the coaching efficacy model and the CES have also been used as a basis and measurement tool respectively, for research investigating athletes' perceptions of their coach. This category of research also uses Horn's (2008) work and model of coaching effectiveness as a foundation, where coach behaviour is stated to influence athletes' perceptions of such behaviour, and these perceptions impact athletes' self-perceptions and ultimately an athletes' motivation and performance. So with the importance of athletes' perceptions being highlighted in effective coaching models, researchers have sought to 
investigate the various perceptions athletes have of their coach, and what impact this may have for certain athlete outcomes.

Smith et al. (1978) were among the first researchers to examine coach behaviours and compare coach and athlete ratings. They found that the relationship between observed coaching behaviours and the coaches' perceptions of their behaviours were generally low and nonsignificant suggesting coaches had little awareness of how frequently they behaved in various ways. On the other hand, athletes' perceptions of coaching behaviours correlated more highly with observed coaching behaviour, with athletes preferring coaches who provided more technical instruction, reinforcement, and mistake contingent reinforcement behaviours. Kenow and Williams $(1992,1999)$ also assessed coach behaviours and athlete perceptions. They found coaches rated their behaviours more positively than athletes did. Further findings from this study were that athletes experiencing higher trait anxiety, higher state cognitive anxiety and lower state self-confidence evaluated their coach's behaviour more negatively than other athletes (Kenow \& Williams, 1992). Kenow and Williams (1999) also found support for somatic anxiety and coach-athlete compatibility as variables associated with athletes' perceptions and evaluations of coaching behaviours. A study by Vargas-Tonsing et al. (2004) also compared coaches' and athletes' perceptions. This study used an alternative method to the CES to assess coaches' and players' perceptions of the frequency and effectiveness of efficacy enhancing techniques, finding that perceptions were generally incongruent between coaches and athletes.

\section{Athletes'perceptions of coaching efficacy}

One area of focus for research investigating athletes' perceptions of their coach, has been athletes' perceptions of their coach's efficacy, typically investigating either the 
comparison between athlete and coach perceptions (Short \& Short, 2004; Teatro et al., 2017), or solely athlete perceptions of their coach (Atkinson et al., 2018; Boardley et al., 2015).

With coaching efficacy being proposed as a central component of effective coaching, much of this area of research has been based upon the elements of the coaching efficacy model proposed by Feltz et al. (1999). In a study by Short and Short (2004), male football coaches' assessments of their coaching efficacy were compared with the perceptions of the athletes from the teams they coached. Following the last game of the season, Short and Short (2004) administered the CES (Feltz et al., 1999) to the coaches, and a modified version of the CES to the athletes. Analyses demonstrated that, on average, coaches rated themselves high on all coaching efficacy subscales and ultimately for total coaching efficacy. The majority of coaches (78\%) rated themselves higher than their athletes did in terms of their total coaching efficacy, although all coach ratings fell within the $95 \%$ confidence interval of their athletes' ratings.

Using the CES (Feltz et al., 1999) and a modified version of the CES (Short \& Short, 2004), Teatro et al. (2017) investigated the relationships between American high school coaches' efficacy beliefs and stakeholders' views of coaching efficacy. They found that the coaches rated themselves significantly higher on all four efficacy domains compared to the ratings of athletes and parents, but there were no differences between athlete and parent scores. Further findings in this study were that although relatively high levels of coaching efficacy were reported by coaches, they reported the lowest efficacy for the motivation dimension, which was echoed by athletes who also scored coaches the lowest in motivation efficacy. The highest efficacy dimension reported by athletes in this study was of their perception of their coaches' character building efficacy. 
Across three separate studies, Boardley et al. (2015) assessed the relationship between golfers' perceptions of their coach's motivation efficacy and golfers' task self-efficacy. As a collective, the three studies showed consistent and meaningful positive links between golfers' perceptions of their coach's motivation efficacy and their task self-efficacy. The strength of association ranged from weak-to-moderate in study 1 , to moderate-to-strong in study 3 . In a study by Atkinson et al. (2018) examining the relationship among college soccer players' perceptions of their coach's efficacy and their team's efficacy, a canonical correlation analysis indicated the relationship to be statistically significant. Specifically, athletes' perceptions of their coach's motivation and game strategy efficacy were the most predictive of athletes' belief in their team's ability to prepare, persist and unite during competition. The overall consensus from the research regarding athletes' perceptions of their coach's efficacy matches the findings of research investigating coaches' self-reported coaching efficacy in terms of the positive athlete-related outcomes associated with higher coaching efficacy levels, and thus suggesting high efficacy coaches to be more effective coaches.

\section{Athletes'perceptions of coaching competency}

Athletes' perceptions of their coaches' competency has been an area of research where athletes' perceptions of their coach have been investigated. Coaching competency is an important element in models of coaching effectiveness (Horn, 2002), which makes the measurement of this construct a key focus area. Perceptions of coach competency represent 'athletes' evaluations of their head coach's ability to affect their learning and performance' (Myers, Feltz et al., 2006). Much of the coaching competency research is derived from the work and findings of studies using the coaching efficacy model (Feltz et al., 1999).

In a study examining athletes' perceptions of their coach's competency in college 
ice-hockey and football players, Myers, Feltz et al. (2006) found that coaching competency consists of the same four dimensions that make up coaching efficacy. Conceptualising that athletes' perceptions of their coach's competency are multidimensional and multilevel, Myers, Feltz et al. (2006) provided initial validation for the multidimensional measures of coaching competency derived from the coaching competency scale (CCS). Myers, Feltz et al. (2006) created the CCS as an instrument to measure coaching competency by making minor revisions to the CES (Feltz et al., 1999).

Further validating evidence for the multidimensional measures of coaching competency derived from the CSS, came from a study by Myers, Wolfe et al. (2006). This study examined the original rating scale structure for the CSS and found positive validity evidence for a condensed post hoc rating scale structure. Myers, Wolfe et al. (2006) also tested how the measures of coaching competency related to athletes' satisfaction with their head coach within and between teams. Athletes' perceptions of their coach's motivation competency had a moderate-to-large positive relationship with athletes' satisfaction with their coach at the athlete level, whereas no relationship was detected at the team level after controlling for athlete-level effects. In a sample of field hockey and netball athletes, Boardley and Kavussanu (2009) examined the relationships between athletes' perceptions of their coach's character building competency (using the character building subscale of the CCS), athletes' perceived motivational climate, athletes' levels of moral disengagement, and the frequency of athletes' prosocial and antisocial behaviours in sport. Athletes' perceptions of their coach's character building competency was found to have very strong negative effects on antisocial opponent and team-mate behaviour, and a weak positive effect upon athletes' prosocial opponent behaviour. Moral disengagement fully mediated the effects of perceived character building competency on prosocial and antisocial opponent behaviours, and partially 
mediated antisocial team-mate behaviour.

A revised version of the CCS was developed for athletes of high school teams (APCCS II-HST) in a study conducted by Myers et al. (2010) to improve the measurement of athletes' evaluations of their head coach's coaching competency. Exploratory multilevel CFA provided evidence for close fit for a five-factor within-teams structure, and a one-factor between-teams structure. Multigroup CFA provided evidence for factorial invariance, except for one for one residual variance, by athlete gender. Evidence for the predictive validity for the ability of the measures derived from the APCCS II-HST to predict satisfaction with the head coach was provided by a study by Myers, Beauchamp et al. (2011). This study assessed the relationship between athletes' perceptions of their coach's competency using the APCCS II-HST and satisfaction with the coach. Findings demonstrated that at the athlete-level, athletes' perceptions of their coach's motivation and technique competency had large positive statistically significant effects on athletes' satisfaction with their coach, explaining $51.8 \%$ of the variance. At the team-level, athletes' perceptions of their coach's total coaching competency had a large positive statistically significant effect on athletes' satisfaction with their coach, explaining $88.3 \%$ of its variance.

Bosselut et al. (2012) assessed relations between athletes' perceptions of their coach's technique and game strategy competency and four dimensions of role ambiguity in offensive and defensive contexts. Analyses highlighted that overall, when controlling for gender, status, and their interaction, increased ambiguity in offensive and defensive contexts was linked with increased criticality of coach's technique and game strategy competency. Specifically, findings showed that at the individual level in the offensive context, $12.86 \%$ of the variance in technique competency was explained by scope of responsibilities, $7.82 \%$ by role behaviors, $7.43 \%$ by role evaluation, and $6.90 \%$ by role consequences. At the individual level 
in the defensive context, $3.58 \%$ of the variance in technique competency was explained by scope of responsibilities, $6.10 \%$ by role behaviors and by role evaluation, and $1.86 \%$ by role consequences. Whereas, at the team-level, the variance in perceptions of technique competency was only explained by role evaluation in offensive (i.e. 12.89\%) and defensive (i.e. $12.44 \%$ ) contexts.

Analyses also demonstrated that at the individual level in the offensive context, $10.59 \%$ of the variance of game strategy competency was explained by scope of responsibilities, $6.72 \%$ by role behaviors, $8.15 \%$ by role evaluation, and $5.44 \%$ by role consequences. In the defensive context, $8.30 \%$ of the variance in game strategy competency was explained by scope of responsibilities, $9.30 \%$ by role behaviors, $8.44 \%$ by role evaluation, and $3.86 \%$ by role consequences. However, at the team-level, role behaviours (i.e. 1.69\%), scope of responsibilities (i.e. 5.65\%) and role evaluation (i.e. 10.45\%) explained significant amounts of variance in perceptions of game strategy competency in the offensive context. Only role evaluation (i.e. $12.71 \%$ ) explained variance in perceptions of game strategy competency in the defensive context.

Malete et al. (2013) examined the influence of athletes' perceptions of coaching competency on peer cheating and aggression. Analyses demonstrated that athletes' perceptions of their coach's game strategy competency was a weak but positive predictor of players' self-reported likelihood to aggress and peer cheating at the within-level. However, athletes' perceptions of their coach's character building competency were not associated with either anti-social behaviours. Re-analysing data from previous coaching competency studies (Malete et al., 2013; Myers et al., 2010), Myers (2013) provided a substantive-methodological synergy. This work demonstrated that the ESEM framework should be considered in subsequent validity studies for new and/or existing instruments (e.g. 
APCCS II-HST and CCS) in the psychology of sport and exercise. The findings from research investigating coaching competency suggest that positive athlete-related outcomes are associated with more competent coaches, and thus suggesting highly competent coaches to be more effective coaches. The research findings have also highlighted the need for the measurement of athletes' evaluations of their coach's competency within the conceptual models of effective coaching.

\section{Athletes'perceptions of coaching effectiveness}

The effective coaching literature has been heavily dominated by research using the coaching efficacy model as a foundation. The dimensionality of the coaching efficacy model (Feltz et al., 1999) and the use of the CES (Feltz et al., 1999) and it's adaptations (Myers, Feltz, Chase et al., 2008; Myers, Feltz et al., 2006; Myers et al., 2010) have been heavily supported over the past two decades of research investigating both coaching efficacy and coaching competency. This framework and measurement tool, as well as conceptual models of coaching effectiveness (Horn, 2002, 2008), have also been supported when athletes' perceptions of their coach's effectiveness have been studied (Boardley et al., 2008; Kassim \& Boardley, 2018; Kavussanu et al., 2008).

Kavussanu et al. (2008) conducted a study investigating athletes' perceptions of coaching effectiveness and coaches' reported coaching efficacy, comparing between the two and also examining predictors. British university athletes $(n=291)$ and their head coaches $(n$ $=26$ ) from eight individual and seven team sports participated in the study. Kavussanu et al. (2008) modified the CES to assess athletes' perceptions of their coach's effectiveness. The stem from the original CES was altered to "How effective is your coach in his/her ability to...", with athletes rating how effective they perceived their coach to be for the 24 items of 
the original CES (Feltz et al., 1999). Findings from the study showed that sport experience of the athlete negatively predicted their perception of their coach's effectiveness for overall coaching effectiveness and for all four dimensions of coaching efficacy. In other terms, the more experience an athlete had, the lower they rated their coach's effectiveness. Effect sizes were small to small-to-medium for this finding, with the finding explained through the assumption that athletes with increased sporting experience are more likely to have been exposed to a greater variety of coaching styles and behaviours that may facilitate a more critical evaluation of coaches. Kavussanu et al. (2008) found no effect of athlete sex on athletes' perceptions of their coach's effectiveness for any dimension of coaching effectiveness. This is contrasting to Horn's model of coaching effectiveness (2002), which proposes athlete sex may influence athletes' perception of their coach's behaviour.

Another finding from this study is that coaches rated themselves significantly higher regarding overall coaching efficacy and for all coaching efficacy dimensions in comparison to their athletes ratings of coaching effectiveness. For example, $42 \%$ and $58 \%$ of the coaches' rated themselves higher regarding the motivation and technique constructs respectively, in comparison to their athletes' ratings. This finding is consistent with the work of Short and Short (2004), and also suggests that coaching efficacy levels do not necessarily transfer to athletes, so consideration of athletes' perceptions of their coach is also required. A further finding from this study was that a mismatch in sex between coach and athlete negatively predicted perceived motivation, and character building. When athletes were coached by coaches of the opposite sex, they perceived their coach to be less effective on the two aforementioned dimensions in comparison to athletes who were coached by coaches of the same sex. It is thought that this may potentially be due to differing instructional and behavioural preferences between males and females. 
Kavusannu et al. (2008) also found that athletes from individual sports rated their coaches as more effective in technique effectiveness compared to team-sport athletes, however ratings did not differ between individual and team-sport athletes for the three other coaching effectiveness dimensions. It was suggested that this finding may be due athletes from individual sports receiving more one-on-one coaching than those in team sports, resulting in individual athletes experiencing more frequent coaching of technique and skills.

Boardley et al. (2008) used the adapted CES (Kavussanu et al., 2008) to measure male rugby union players' perceptions of their coach's effectiveness. They investigated the players' perceptions of their coach on the dimensions of coaching effectiveness as predictors of numerous athlete-level outcomes. Regression analyses (controlling for playing experience) identified players' perceptions of their coach's motivation effectiveness positively predicted player effort, commitment and enjoyment, with small-to-medium effect sizes. Players' perceptions of their coach's technique effectiveness positively predicted players' task self-efficacy, and perceptions of their coach's character building effectiveness positively predicted prosocial behaviours within players (small effect sizes). These findings highlight the positive relationship that exists between players' perceptions of coaching effectiveness and athlete-level outcomes, where perceiving the coach to be high in effectiveness makes athletes more likely to demonstrate or experience desired outcomes to aid or enhance performance or positive behaviour. As well as offering comparative and validating findings to the initial work of Feltz et al. (1999), and support for the coaching efficacy model (Feltz et al., 1999), this study by Boardley et al. (2008) also identifies the importance of assessing each dimension of coaching effectiveness separately, with each dimension relating to different athlete-level outcomes.

Other studies using the adapted version of the CES (Kavussanu et al., 2008) to 
investigate athletes' perceptions of coaching effectiveness include the work of Broodryk and Van Den Berg (2011) and Broodryk et al. (2014). When investigating high school rugby players' perceptions of their coach's effectiveness, Broodryk and Van Den Berg (2011) found that the coaches from larger schools were rated average by players for all coaching effectiveness dimensions except for motivation effectiveness which players perceived their coach to be below average. The players from smaller schools reported their coach to be average for all coaching effectiveness dimensions. Results from the study by Broodryk et al. (2014) echoed the previous findings of Short and Short (2004) and Kavussanu et al. (2008) indicating that coaches and players' perceptions on coaching effectiveness differ. In this study, Broodryk et al. (2014) found that $62 \%$ of coaches rated themselves higher than their players' perceived them to be in terms of their coaching effectiveness.

Research by Kassim and Boardley (2018) investigated whether athlete perceptions of coaching effectiveness predicted athlete-level outcomes in team and individual sports cross-culturally. In this study, the outcomes assessed were the four athlete-level outcomes of effective coaching outlined by Côté and Gilbert (2009). Hierarchical multiple regression analyses (controlling for sex, sport expereince and sport type) indicated that athletes' perceptions of their coach's motivation effectiveness positively predicted athletes' perceived sport confidence and connection with their coach. Athletes' perceptions of their coach's technique effectiveness positively predicted athletes' sport competence, and athletes' perceptions of their coach's character building effectiveness positively predicted athletes' moral identity, an indicator of character. Effect sizes of the findings were consistently larger in the Malaysia sample compared to the UK sample. By linking coaching effectiveness perceptions with athlete-level outcomes, the findings of this study offer support for the conceptual framework outlined by Côté and Gilbert (2009), whereby effective coaching 
should result in the positive development of athletes' competence, confidence, connection and character.

\section{Summary of key findings from within the literature}

This review demonstrated the numerous ways that effective coaching has been investigated within the coaching science literature. The systematic literature search revealed 46 papers investigating effective coaching. These studies were then categorised based upon whether they assessed coaches' perceptions of coaching efficacy utilising the original coaching efficacy scale proposed by Feltz et al. (1999), evaluated and/or revised the original CES (Feltz et al., 1999), or assessed athletes' perceptions of their coach.

As a whole, the reviewed studies utilising the original CES offered support for a number of sources of coaching efficacy. For example, positive relationships were found between coaching experience and coaching efficacy (Feltz et al., 1999; Fung, 2002; Malete \& Sullivan, 2009; Myers, Vargas-Tonsing et al., 2005; Tsorbatzoudis et al., 2003). Next, coach education was found to be a positive predictor of coaching efficacy (Campbell \& Sullivan, 2005; Malete \& Feltz, 2000). Also, higher levels of coaching efficacy were found for coaches with a greater career winning percentage (Feltz et al., 1999; Myers, Vargas-Tonsing et al., 2005). The reviewed studies also revealed perceived athlete-ability (Feltz et al., 1999) and team-ability (Feltz et al., 1999; Myers, Vargas-Tonsing et al., 2005) were positively linked with coaching efficacy. School support (Feltz et al., 1999), community support (Feltz et al., 1999; Myers, Vargas-Tonsing et al., 2005), and parental support (Myers, Vargas-Tonsing et al., 2005) were identified as positive predictors of coaching efficacy. Additionally, emotional intelligence was found to be a positive predictor of coaching efficacy (Hwang et al., 2013; 
Thelwell et al., 2008). Finally, it was found that higher levels of coaching efficacy were predicted by imagery use (Short et al., 2005).

Support for numerous outcomes of coaching efficacy has also been provided in the studies reviewed utilising the original CES. For example, higher winning percentages and higher levels of player satisfaction were found for high-efficacy coaches in comparison to low-efficacy coaches (Feltz et al., 1999). High-efficacy coaches were also found to display more frequent praise and encouragement behaviours, and less instructive and organisational behaviour than low-efficacy coaches (Feltz et al., 1999). No differences were identified between high and low efficacy coaches in terms of their commitment to coaching, amount of perceived coaching effort and their use of punishment and control behaviours (Feltz et al., 1999). Motivation and technique dimensions of coaching efficacy were found to be significant predictors of coaches' training and instruction engagement, as well as positive feedback behaviours (Sullivan \& Kent, 2003). Game strategy efficacy positively predicted athletes' likelihood to aggress in one study (Chow et al., 2009), but not in another (Malete et al., 2013). Game strategy efficacy was also found to positively predict team performance and atmosphere (Keatlholetswe \& Malete, 2013). One study identified a positive relationship between coaching efficacy and leadership style (Hwang et al., 2013), with another identifying that technique efficacy specifically, predicted player perceptions of coach leadership style (Keatlholetswe \& Malete, 2013). Further studies showed that commitment to coaching (Kent \& Sullivan, 2003) and team-efficacy (Vargas-Tonsing et al., 2003) were positively predicted by coaching efficacy. Gender match or mismatch between athletes and coaches was identified to be a moderator of coaching efficacy outcomes (Myers, Vargas-Tonsing et al., 2005). Specifically, Myers, Vargas-Tonsing et al. (2005) found that total coaching efficacy positively predicted coaching behaviour, team satisfaction and winning percentage for men's teams. 
However, total coaching efficacy predicted only coaching behaviour across women's teams with female coaches.

An evaluation of the psychometric properties of the original CES recommended a reduced category rating scale structure (Myers, Wolfe et al., 2005), with support for the condensed rating scale of the CES being provided (Hepler et al., 2007; Myers, Feltz et al., 2008). Studies employing the condensed rating scale identified playing and coaching experience, perceived player improvement, and perceived support to be sources of coaching efficacy (Feltz et al., 2009; Hepler et al., 2007). The CES II-HST (Myers, Feltz, Chase et al., 2008) and CES II-YST (Myers, Chase et al., 2011) were proposed as revised versions of the original CES to improve the measurement of coaching efficacy. Utilisation of the CES II-HST identified career winning percentage was positively linked to game strategy and physical conditioning efficacy, but teams' prior success had a negative relationship with motivation efficacy, with significant effects evident for female coaches only (Myers, Feltz et al., 2011). Further utilisation of the CES II-HST found coach education positively predicted coaching efficacy, and coaching efficacy positively predicted coach leadership behaviours (Sullivan et al., 2012). A meta-analysis supported positive relationships between the sources and dimensions of coaching efficacy proposed in the coaching efficacy model (Feltz et al., 1999), and identified coach gender and level coached moderated the overall relationship.

Studies investigating athletes' perceptions identified differences between coach and athlete perceptions of effective coaching (Kavussanu et al., 2008; Kenow \& Williams, 1992, 1999, Short \& Short, 2004; Teatro et al., 2017; Vargas-Tonsing et al., 2004), with coaches generally rating themselves higher. Further, the reviewed studies highlighted a range of outcomes that result from athletes' perceptions of their coach. With regards to athletes' perceptions of coaching efficacy, positive links were found between golfers' perceptions of 
their coach's motivation efficacy and task self-efficacy (Boardley et al., 2015). A positive relationship was also found between athletes' perceptions of coaching efficacy and their team's efficacy.

With regards to athletes' perceptions of coaching competency, athletes' perceptions of their coach's motivation (Myers, Wolfe et al., 2006) and technique (Myers, Beauchamp et al., 2011; Myers, Wolfe et al., 2006) competency were found to be positive predictors of athletes' satisfaction with their coach. Also, a negative relationship was identified between athletes' perceptions of their coach's character building competency and antisocial opponent and team-mate behaviour (Boardley \& Kavussanu, 2009). One study found a negative relationship between athletes' perceptions of their coach's technique and game strategy competency and role ambiguity (Bosselut et al., 2012). Another study identified that athletes' perceptions of their coach's game strategy competency positively predicted players' self-reported likelihood to aggress and peer cheating (Malete et al., 2013).

With regards to athletes' perceptions of coaching effectiveness, it was found that athletes' sport experience negatively predicted their perception of their coach's effectiveness (Kavussanu et al., 2008). Studies have also highlighted multiple outcomes that result from athletes' perceptions of coaching effectiveness. For example, rugby players' perceptions of their coach's motivation effectiveness positively predicted player effort, commitment and enjoyment (Boardley et al., 2008). Additionally, their perceptions of their coach's technique effectiveness and character building effectiveness positively predicted players' task self-efficacy and prosocial behaviours respectively (Boardley et al., 2008). Another study found that athletes' perceptions of their coach's motivation effectiveness positively predicted athletes' perceived sport confidence and connection with their coach. This study further identified that athletes' perceptions of their coach's technique and character building 
effectiveness positively predicted athletes' sport competence and moral identity respectively (Kassim \& Boardley, 2018). These findings therefore demonstrate the variety in which effective coaching has been investigated, especially regarding the many sources that impact upon and the multiple outcomes that result from effective coaching.

\section{Limitations of the literature}

Despite helping to extend and improve coaching science by further developing the understanding of effective coaching behaviours, including their sources and outcomes, the reviewed literature is not without limitations. Firstly, one limitation is that despite efforts such as the integrative definition of coaching effectiveness proposed by Côté and Gilbert (2009), research has not consistently followed a shared conceptual understanding of coaching effectiveness. In particular, there has been a diverse range of ways in which effective coaching has been explored with regards to sources, dimensions and outcomes. This has also meant that there has been a lack of precise and consistent terminology used throughout the research in this field (Côté \& Gilbert, 2009). For example, the terms 'effectiveness' and 'efficacy' have not always been used in a consistent manner across studies. Coaching effectiveness has typically been used when referring to athlete outcomes of effective coaching, and the ability of coaches to implement their knowledge and skills to influence such outcomes, with athletes' perceptions of their coaches' behaviours acting as a critical variable (Boardley et al., 2008; Côté \& Gilbert, 2009). Whereas, coaching efficacy refers to coaches' own beliefs of their own knowledge and skills, and what they can do with them (Boardley et al., 2008; Feltz et al., 1999). However, there have been studies that have used the term 'efficacy' to assess athletes' perceptions of their coaches' behaviours when in fact 'effectiveness' may have been more appropriate (Atkinson et al., 2018; Boardley et al., 2015; 
Short \& Short, 2004; Teatro et al., 2017).

A second limitation of the reviewed literature is that the majority of studies have used self-report measures to collect data, which means the accuracy of the findings of these particular studies are in part reliant on the honesty of participants, as well as participants' introspective ability to provide an accurate response to questionnaire items. Even with the use of fully validated measures, there is still a possibility that findings from studies employing self-report techniques were affected by issues including social desirability (Gucciardi et al., 2010; Reynolds, 1982) and method effects such as anchoring effects, primacy and recency effects, time pressure, and consistency motivation. (Paulhus \& Vazire, 2007).

A third limitation is that many of the studies in the reviewed literature have used a cross-sectional design, collecting data at single time-points. Although this design method is useful for conducting initial exploratory studies and identifying prevalences of outcomes within populations at a given time point, such designs are limited in that they are unable to establish cause and effect relationships between study variables (Carlson \& Morrison, 2009; Levin, 2006).

Another limitation concerns the studies reviewed comparing coach and athlete ratings (Kavussanu et al., 2008; Kenow \& Williams, 1992, 1999, Short \& Short, 2004; Teatro et al., 2017; Vargas-Tonsing et al., 2004). Such studies have only identified that differences may exist between perceptions of effective coaching behaviours; they have not identified what the implications of such differences may be. Understanding the reasoning behind and the impact of differing perceptions between coaches and athletes regarding effective coaching behaviours is important for both coaches and athletes to ensure optimal coach-athlete functionality and the achievement of positive coach and athlete outcomes. 
A final limitation of the reviewed literature is that although reliable and valid, the measurement scales that have been developed to assess effective coaching mainly focus on coaches' professional knowledge. These scales do not include subscales that completely reflect the forms of interpersonal or intrapersonal knowledge deemed necessary for coaching effectiveness based on the integrative definition proposed by Côté and Gilbert (2009). Therefore, the literature has not specifically investigated all elements of coaching effectiveness, and the impact of such dimensions for each of the four athlete-level outcomes outlined as outcomes of effective coaching by Côté and Gilbert (2009).

Lastly, even though the review was based on a comprehensive systematic search of four relevant electronic databases, the review itself is not without its own limitations. It is possible that there is some published literature that may not have been identified and included in this review. There may also have been research studies conducted but not published by researchers due to finding non-significant or weak effects between study variables, resulting in the review potentially having a degree of bias towards studies reporting significant and stronger effects. The review should therefore be interpreted with this in mind.

\section{Future research}

To help address the limitations identified within the existing literature, future research should look to follow a consistent and shared conceptual and methodological approach to continue to move the field of literature forward. Aligning individual studies within an integrative theoretical framework of effective coaching will enable the integration of findings and result in a more coherent understanding of effective coaching. This will then allow coaching practice to advance and ultimately lead to athletes and coaches experiencing more positive and beneficial outcomes in sport coaching environments. The integrative definition 
of coaching effectiveness proposed by Côté and Gilbert (2009) is recommended as an avenue for such cohesion of future studies, where consideration should be given to all elements suggested within the definition (i.e. coaches' knowledge, athletes' outcomes and coaching contexts). Future studies should continue to refine existing models of effective coaching, and validate measures in a variety of different samples.

Future research should look to employ more experimental and longitudinal research designs to examine relationships between variables, testing the causal nature between sources, dimensions and outcomes of effective coaching proposed in conceptual models. For example, aspects of effective coaching could be manipulated (e.g. through coach development programmes) to determine their effect on athlete outcomes. Utilisation of longitudinal designs will allow for the temporal ordering of the effects identified between variables to be investigated. Alternative or additional methods of assessment such as other-report and objective measures should also be considered in future research investigating the sources, dimensions and outcomes of effective coaching.

To further address the limitations highlighted within the existing effective coaching literature, future research should develop a measurement scale that incorporates assessment of professional, interpersonal and intrapersonal forms of coach knowledge, deemed essential for coaching effectiveness (Côté and Gilbert, 2009). This will allow future studies to investigate all proposed elements of effective coach knowledge and the impact each form of knowledge has upon specific athlete outcomes, particularly the $4 \mathrm{C}$ 's, which have been highlighted as desirable outcomes in the effective coaching literature (Boardley, 2018; Côté and Gilbert, 2009). 


\section{Conclusion}

The aim of this critical scoping review was to provide an up-to-date and comprehensive overview of the effective coaching literature. This review highlights that the field is in its infancy, and there are many ways that effective coaching can be assessed and explored. This review offers a framework identifying the revisions made within the literature and how effective coaching has been narrowed down over time into key areas. It has been identified within this review that there are two main areas of the effective coaching literature. One is coaches' perceptions of their own coaching behaviour. This can be broken down into sub-areas focusing on the sources and outcomes of coaches' perceptions of coaching efficacy. The other main area of effective coaching is athletes' perceptions of their coach's behaviour. This area can be broken down into sub-areas focusing on the sources and outcomes of athletes' perceptions of coaching efficacy, competency and effectiveness.

Although the reviewed literature offers significant information and insight with regards to the importance of coaching behaviours (e.g. in shaping an athlete's psychological development and well-being), it does highlight some limitations that exist within the existing literature. From a systematic review or meta-analysis perspective, the literature is not yet at a point where we could meta-analyse or systematically review the literature and gain much from it. This is because there is little alignment across the few studies with regards to the specifics of how effective coaching is being explored. The assessment of coaching efficacy, competency, and effectiveness, and the perspective from which they have been assessed (i.e. coach or athlete) has consisted of multiple measurements being used across studies to assess a range of sources and outcomes of effective coaching.

To help continue and advance the important research conducted thus far in this domain, a consistent and shared conceptual and methodological approach is needed for the 
way that effective coaching is assessed to further enhance our understanding of effective coaching. It appears that the field of literature is now taking steps forwards in achieving this, as further refinements are made to the models and the validation of measures in multiple different samples. As the field matures, it will enable more coherence around the different key areas of effective coaching and allow the use of consistent measures so we then can start to see how effective coaching and the frameworks that have been proposed actually influence positive developmental outcomes for athletes and coaches. 


\section{Declaration of interest statement}

The authors report no conflicts of interest that have impacted upon the generation of this review. 


\section{References}

1. Atkinson, F., Short, S. E., \& Martin, J. (2018). College soccer players' perceptions of coach and team efficacy. The Sport Psychologist, 32(3), 237-243.

2. Bandura, A. (1997). Self-efficacy: The exercise of control. New York: Freeman

3. Bandura, A. (1986). Social foundations of thought and action: A social cognitive theory. Englewood Cliffs, NJ: Prentice Hall.

4. Bandura, A. (1977). Self-efficacy: Toward a unifying theory of behavioral change. Psychological Review, 84(2), 191-215.

5. Boardley, I. D. (2018). Coaching efficacy research: learning from the past and looking to the future. International Review of Sport and Exercise Psychology, 11(1), 214-237.

6. Boardley, I. D., Jackson, B., \& Simmons, A. (2015). Changes in task self-efficacy and emotion across competitive performances in golf. Journal of Sport and Exercise Psychology, 37(4), 393-409.

7. Boardley, I. D., \& Kavussanu, M. (2009). The influence of social variables and moral disengagement on prosocial and antisocial behaviours in field hockey and netball. Journal of sports sciences, 27(8), 843-854.

8. Boardley, I. D., Kavussanu, M., \& Ring, C. (2008). Athletes' perceptions of coaching effectiveness and athlete-related outcomes in rugby union: An investigation based on the coaching efficacy model. The sport psychologist, 22(3), 269-287.

9. Bosselut, G., Heuzé, J. P., Eys, M. A., Fontayne, P., \& Sarrazin, P. (2012). Athletes' perceptions of role ambiguity and coaching competency in sport teams: A multilevel analysis. Journal of Sport and Exercise Psychology, 34(3), 345-364. 
10. Broodryk, R., \& Van Den Berg, P. H. (2011). High School Rugby Players' Perception of Coaching Effectiveness. Online Submission.

11. Broodryk, R., Van den Berg, P. H., Kruger, A., \& Ellis, S. M. (2014). Comparing club level rugby coaches and players' perceptions of coaching effectiveness:: sport psychology. African Journal for Physical Health Education, Recreation and Dance, 20(Issue-22), 780-792.

12. Campbell, T., \& Sullivan, P. (2005). The Effect of a Standardized Coaching Education Program on the Efficacy of Novice Coaches. Avante, 11(1).

13. Carlson, M. D., \& Morrison, R. S. (2009). Study design, precision, and validity in observational studies. Journal of palliative medicine, 12(1), 77-82.

14. Chow, G. M., Murray, K. E., \& Feltz, D. L. (2009). Individual, team, and coach predictors of players' likelihood to aggress in youth soccer. Journal of Sport and Exercise Psychology, 31(4), 425-443.

15. Côté, J., \& Gilbert, W. (2009). An integrative definition of coaching effectiveness and expertise. International journal of sports science \& coaching, 4(3), 307-323.

16. Denham, C. H., \& Michael, J. J. (1981). Teacher Sense of Efficacy: A Definition of the Construct and a Model for Further Research. Educational Research Quarterly, $6(1), 39-63$.

17. Feltz, D. L. (1988). Self-confidence and sports performance. 423-457. Exercise and Sport Sciences Reviews. MacMillan, New York.

18. Feltz, D. L., Chase, M. A., Moritz, S. E., \& Sullivan, P. J. (1999). A conceptual model of coaching efficacy: Preliminary investigation and instrument development. Journal of educational psychology, 91(4), 765. 
19. Feltz, D. L., Hepler, T. J., Roman, N., \& Paiement, C. (2009). Coaching efficacy and volunteer youth sport coaches. The sport psychologist, 23(1), 24-41.

20. Fung, L. (2003). Assessment: Coaching efficacy as indicators of coach education program needs. Athletic Insight, 5.

21. Fung, L. (2002). Task familiarity and task efficacy: A study of sports coaches. Perceptual and motor skills, 95(2), 367-372.

22. Gucciardi, D. F., Jalleh, G., \& Donovan, R. J. (2010). Does social desirability influence the relationship between doping attitudes and doping susceptibility in athletes?. Psychology of sport and exercise, 11(6), 479-486.

23. Hepler, T. J., Feltz, D. L., Roman, N., \& Paiement, C. A. (2007). Validating the coaching efficacy scale for youth sport coaches. Journal of Sport \& Exercise Psychology, 29.

24. Horn, T. S. (2002). Coaching Effectiveness In The Sports Domain. In T. S. Horn (Ed.), Advances In Sport Psychology. 2nd Ed. Champaign, IL: Human Kinetics.

25. Horn, T. S. (2008). Coaching Effectiveness In The Sports Domain. In T. S. Horn (Ed.), Advances In Sport Psychology. 3rd Ed. Champaign, IL: Human Kinetics.

26. Hwang, S., Feltz, D. L., \& Lee, J. D. (2013). Emotional intelligence in coaching: Mediation effect of coaching efficacy on the relationship between emotional intelligence and leadership style. International Journal of Sport and Exercise Psychology, 11(3), 292-306.

27. Kassim, A. F. M., \& Boardley, I. D. (2018). Athlete perceptions of coaching effectiveness and athlete-level outcomes in team and individual sports: a cross-cultural investigation. The Sport Psychologist, 32(3), 189-198. 
28. Kavussanu, M., Boardley, I. D., Jutkiewicz, N., Vincent, S., \& Ring, C. (2008). Coaching efficacy and coaching effectiveness: Examining their predictors and comparing coaches' and athletes' reports. The Sport Psychologist, 22(4), 383-404.

29. Keatlholetswe, L., \& Malete, L. (2019). Coaching Efficacy, Player Perceptions of Coaches' Leadership Styles, and Team Performance in Premier League Soccer. Research quarterly for exercise and sport, 90(1), 71-79.

30. Kenow, L., \& Williams, J. M. (1999). Coach-athlete compatibility and athlete's perception of coaching behaviors. Journal of Sport Behaviour, 22, 251-259.

31. Kenow, L. J., \& Williams, J. M. (1992). Relationship between anxiety, self-confidence, and evaluation of coaching behaviors. The Sport Psychologist, 6(4), $344-357$.

32. Kent, A., \& Sullivan, P. J. (2003). Coaching efficacy as a predictor of university coaches' commitment. International Sports Journal, 7(1), 78.

33. Levin, K. A. (2006). Study design III: Cross-sectional studies. Evidence-based dentistry, 7(1), 24-25.

34. Lyle, J. (2002). Sports coaching concepts: A framework for coaches' behaviour. Psychology Press.

35. Malete, L., Chow, G. M., \& Feltz, D. L. (2013). Influence of coaching efficacy and coaching competency on athlete-level moral variables in B otswana youth soccer. Journal of Applied Social Psychology, 43(10), 2107-2119.

36. Malete, L., \& Feltz, D. L. (2000). The effect of a coaching education program on coaching efficacy. The Sport Psychologist, 14(4), 410-417.

37. Malete, L., \& Sullivan, P. (2009). Sources of coaching efficacy in coaches in Botswana. International Journal of Coaching Science, 3(1). 
38. Mills, J. P., \& Boardley, I. D. (2016). Advancing leadership in sport: Time to 'actually' take the blinkers off? Sports Medicine, 47(3), 565-570.

39. Mills, J. P., \& Boardley, I. D. (2017). Development and initial validation of an indirect measure of transformational leadership integrity. Psychology of Sport and Exercise, 32, 34-46. https://doi.org/10.1016/j.psychsport.2017.05.005

40. Moher, D., Liberati, A., Tetzlaff, J., Altman, D. G., \& Group, T. P. (2009). Preferred Reporting Items for Systematic Reviews and Meta-Analyses: The PRISMA Statement. PLOS Medicine, 6(7), e1000097.

41. Myers, N. D. (2013). Coaching competency and (exploratory) structural equation modeling: A substantive-methodological synergy. Psychology of Sport and Exercise, 14(5), 709-718.

42. Myers, N. D., Beauchamp, M. R., \& Chase, M. A. (2011). Coaching competency and satisfaction with the coach: A multi-level structural equation model. Journal of sports sciences, 29(4), 411-422.

43. Myers, N. D., Chase, M. A., Beauchamp, M. R., \& Jackson, B. (2010). Athletes' perceptions of coaching competency scale II-High school teams. Educational and Psychological Measurement, 70(3), 477-494.

44. Myers, N. D., Chase, M. A., Pierce, S. W., \& Martin, E. (2011). Coaching efficacy and exploratory structural equation modeling: A substantive-methodological synergy. Journal of Sport and Exercise Psychology, 33(6), 779-806.

45. Myers, N., Feltz, D., \& Chase, M. (2011). Proposed modifications to the conceptual model of coaching efficacy and additional validity evidence for the coaching efficacy scale II-high school teams. Research quarterly for exercise and sport, 82(1), 79-88. 
46. Myers, N. D., Feltz, D. L., Chase, M. A., Reckase, M. D., \& Hancock, G. R. (2008). The coaching efficacy scale II—High school teams. Educational and Psychological Measurement, 68(6), 1059-1076.

47. Myers, N. D., Feltz, D. L., Maier, K. S., Wolfe, E. W., \& Reckase, M. D. (2006). Athletes' evaluations of their head coach's coaching competency. Research quarterly for exercise and sport, 77(1), 111-121.

48. Myers, N. D., Feltz, D. L., \& Wolfe, E. W. (2008). A confirmatory study of rating scale category effectiveness for the coaching efficacy scale. Research Quarterly for Exercise and Sport, 79(3), 300-311.

49. Myers, N. D., Park, S. E., Ahn, S., Lee, S., Sullivan, P. J., \& Feltz, D. L. (2017). Proposed sources of coaching efficacy: a meta-analysis. Journal of Sport and Exercise Psychology, 39(4), 261-276.

50. Myers, N. D., Vargas-Tonsing, T. M., \& Feltz, D. L. (2005). Coaching efficacy in intercollegiate coaches: Sources, coaching behavior, and team variables. Psychology of Sport and Exercise, 6(1), 129-143.

51. Myers, N. D., Wolfe, E. W., \& Feltz, D. L. (2005). An evaluation of the psychometric properties of the coaching efficacy scale for coaches from the United States of America. Measurement in Physical Education and Exercise Science, 9(3), 135-160.

52. Myers, N. D., Wolfe, E. W., Maier, K. S., Feltz, D. L., \& Reckase, M. D. (2006). Extending validity evidence for multidimensional measures of coaching competency. Research Quarterly for Exercise and Sport, 77(4), 451-463.

53. National Association for Sport and Physical Education. (1995) Quality coaches, quality sports: National standards for athletic coaches. Dubuque, IA: Kendall/Hunt. 
54. Park, J. K. (1992). Construction of the coaching confidence scale. Unpublished doctoral dissertation. Michigan State University, East Lansing

55. Paulhus, D. L., \& Vazire, S. (2007). The self-report method. Handbook of research methods in personality psychology, 1, 224-239.

56. Reynolds, W. M. (1982). Development of reliable and valid short forms of the Marlowe-Crowne Social Desirability Scale. Journal of clinical psychology, 38(1), $119-125$.

57. Seefeldt, V., \& Brown, E. W. (1990). Program for athletic coaches' education (PACE). Benchmark Press.

58. Short, S. E., \& Short, M. W. (2004). Coaches' assessment of their coaching efficacy compared to athletes' perceptions. Perceptual and Motor Skills, 99(2), 729-736.

59. Short, S. E., Smiley, M., \& Ross-Stewart, L. (2005). The relationship between efficacy beliefs and imagery use in coaches. The Sport Psychologist, 19(4), 380-394.

60. Smith, R. E., Smoll, F. L., \& Curtis, B. (1979). Coach effectiveness training: A cognitive-behavioral approach to enhancing relationship skills in youth sport coaches. Journal of Sport and Exercise Psychology, 1(1), 59-75.

61. Smith, R. E., Smoll, F. L., \& Curtis, B. (1978). Coaching behaviors in little league baseball. Psychological perspectives in youth sports, 173, 201-208.

62. Smoll, F. L., \& Smith, R. E. (1989). Leadership Behaviors in Sport: A Theoretical Model and Research Paradigm 1. Journal of applied social psychology, 19(18), $1522-1551$.

63. Sullivan, P. J., \& Kent, A. (2003). Coaching efficacy as a predictor of leadership style in intercollegiate athletics. Journal of Applied Sport Psychology, 15(1), 1-11. 
64. Sullivan, P., Paquette, K. J., Holt, N. L., \& Bloom, G. A. (2012). The relation of coaching context and coach education to coaching efficacy and perceived leadership behaviors in youth sport. The sport psychologist, 26(1), 122-134.

65. Teatro, C., Thompson, M., Kulinna, P. H., Mars, H. V. D., \& Kwan, J. (2017).

Coaching behaviors and stakeholders' views of coaches' efficacy. International Journal of Sports Science \& Coaching, 12(4), 452-460.

66. Thelwell, R. C., Lane, A. M., Weston, N. J., \& Greenlees, I. A. (2008). Examining relationships between emotional intelligence and coaching efficacy. International Journal of Sport and Exercise Psychology, 6(2), 224-235.

67. Tsorbatzoudis, H., Daroglou, G., Zahariadis, P., \& Grouios, G. (2003). Examination of coaches' self-efficacy: Preliminary analysis of the coaching efficacy scale. Perceptual and motor skills, 97(3_suppl), 1297-1306.

68. Tsorbatzoudis, H., Zahariadis, P., Daroglou, G., Grouios, G. (2000) Preliminary study of Coaches' Self-efficacy Scale. Proceedings of the 6th Greek Congress on Sport Psychology. Athens: Congress. Pp. 58-61.

69. Vargas-Tonsing, T. M., Myers, N. D., \& Feltz, D. L. (2004). Coaches' and athletes' perceptions of efficacy-enhancing techniques. The Sport Psychologist, 18(4), 397-414.

70. Vargas-Tonsing, T. M., Warners, A. L., \& Feltz, D. L. (2003). The predictability of coaching efficacy on team efficacy and player efficacy in volleyball. Journal of sport behavior, 26(4).

71. Vella, S. A., Oades, L. G., \& Crowe, T. P. (2010). The application of coach leadership models to coaching practice: Current state and future directions. International Journal of Sports Science \& Coaching, 5(3), 425-434. 
Figures

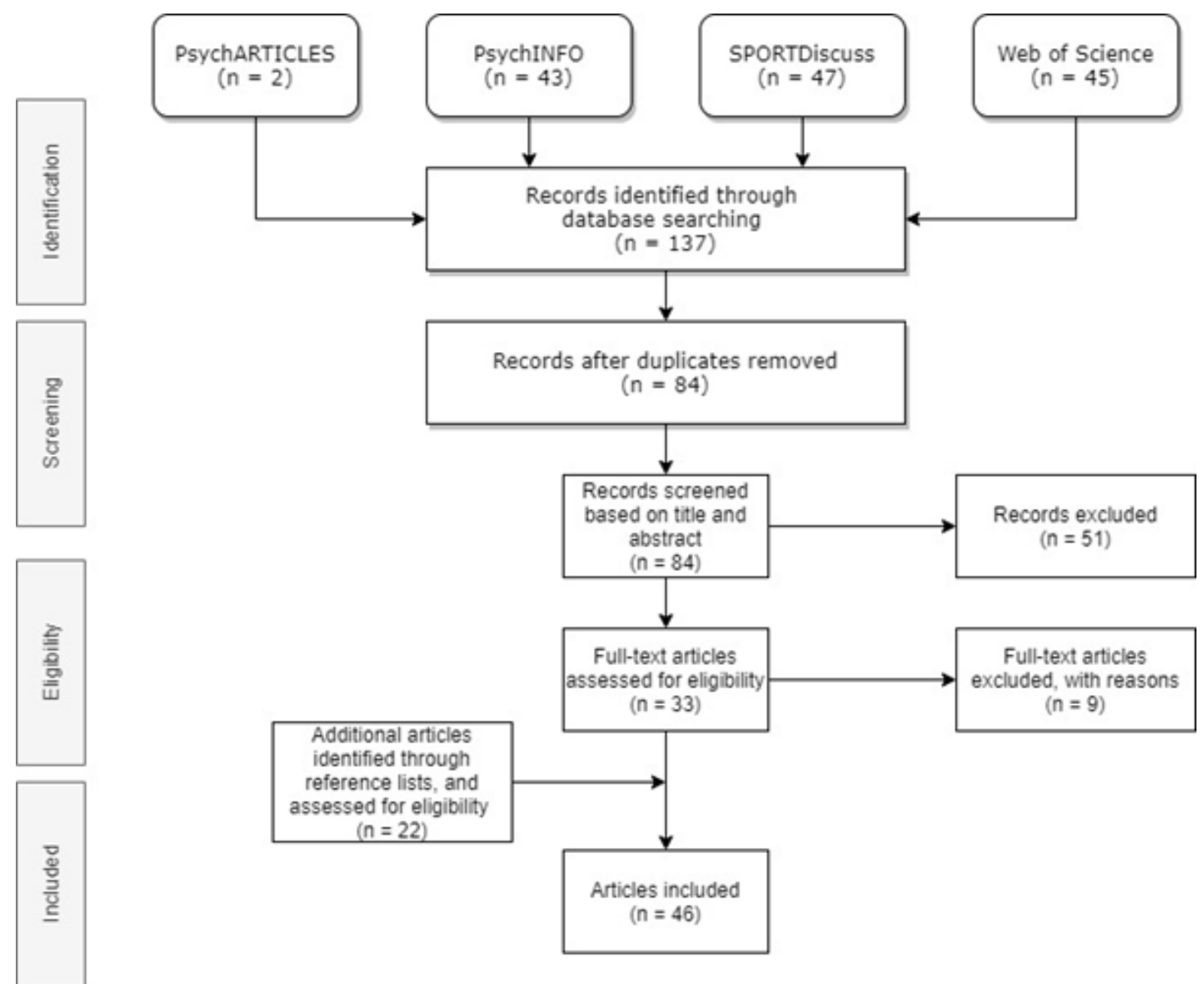

Figure 1. PRISMA flow diagram of the systematic literature research (Adapted from Moher et al. 2009)) 